\title{
The knowledge, attitude and behaviours of nurses about pharmacovigilance, adverse drug reaction and adverse event reporting in a state hospital
}

\author{
Fisun Vural ${ }^{1}$, Seval Ciftci ${ }^{2}$, Birol Vural ${ }^{3}$ \\ ${ }^{1}$ Haydarpasa Numune Training and Research Hospital, Istanbul, Turkey; \\ ${ }^{2}$ Golcuk Necati Celik State Hospital, Kocaeli, Turkey; \\ ${ }^{3}$ Kocaeli University, School of Medicine, Kocaeli, Turkey
}

\begin{abstract}
OBJECTIVE: With the use of any drug comes the possibility of unintended consequences which when harmful are referred to as adverse drug reactions (ADRs). The development of national pharmacovigilance systems is the responsibility of all health workers. The aim of this study was to investigate the knowledge of nurses about pharmacovigilance and attitudes about ADR and adverse event reporting.
\end{abstract}

METHODS: This descriptive-cross sectional study was performed in 112 nurses working in a public hospital. The questionnaire was applied about pharmacovigilance and adverse drug reactions. The knowledge, attitudes and practices about adverse drug reactions were asked.

RESULTS: The $74.1 \%$ of the nurses definition of "severe adverse effect" of drug therapy. The ratio of participants who knew that ADRs are reported to contact person responsible from pharmacovigilance was $34.9 \%$. Although $70.5 \%$ of nurses knew the necessity of ADR reporting, the $8 \%$ of the nurses knew Turkish Pharmacovigilance Center (TÜFAM). Only $8 \%$ of nurses reported ADRs in their professionality.

CONCLUSION: Although most of the participants knew the importance of ADR event reporting, event reporting was low. Thiese results showed that there is a lack of knowledge about pharmacovigilance. Futher studies with different settings and healthcare staff are needed to improve awareness about pharmacovigilance.

Key words: Drug reactions; drug safety; pharmacovigilance.

$\mathrm{T}$ he World Health Organization (WHO) defined adverse drug reaction (ADR) as harmful, and unwanted reaction of a drug when used in normal doses for human beings. Pharmacovigilance was defined as a branch of science and related activities interested in the determination, evaluation of drug safety, and taking necessary relevant measures [1-3].

At the beginning of 1900s German scien-

Received: September 11, 2014 Accepted: December 01, 2014 Online: January 24, 2015

Correspondence: Dr. Fisun VURAL. Haydarpasa Numune Egitim ve Arastirma Hastanesi, Istanbul, Turkey.

Tel: +90 216 - 4144524 e-mail: fisunvural@yahoo.com.tr

(c) Copyright 2014 by Istanbul Northern Anatolian Association of Public Hospitals - Available online at www.kuzeyklinikleri.com 
tist Paul Elrich defined the ideal drug as "a magic bullet"which directly reaches the region of the disease, and does not cause any harm to healthy tissues." Drugs exert their effects on diseased region, and also harm healthy tissues as well [1]. Firstly in the year 1848, chloroform used during operation performed for the extraction of an ingrown toe nail in a pediatric patient named Hannah Greener induced development of atrial fibrillation ensuing in death of the patient. From then on, potential fatal adverse effects of the drugs attracted widespread attention [4] However, priorly in 1893 Lancet started to record adverse effects of the drugs [5]. In 1906, FDA laid down the rules stating that drugs should be formulated in their pure forms ie. free from other chemical substances. In the year 1936 sulphanilamide dissolved in ethylene glycol caused the death of 107 patients. This tragic event led the way to enact pharmacovigilance laws [4]. At the end of 1950 s, emergence of cases with phocomelia secondary to thalidomide prescribed as a sedative in pregnant women shocked the whole world. Especially Germany where the drug first marketed was especially affected from harmful effects of the drug, and nearly 10.000 fetuses worldwide were exposed to teratogenic effects of the drug [6]. Though priorly, cases with phocomelia were thought to develop because of environmental teratogens, firstly in 1961 the cases with phocomelia caused by thalidomide were published in Lancet which led to enactment of the drug safety law [7]. Legal regulations known as Kefauer-Harris amendments banned the use of unsafe drugs whatever was their effectiveness would be [6]. These dramatic events experienced related to drug safety emphasized the importance of pharmacovigilance systems and Phase IV studies, and initiated the establishment of pharmacovigilance systems in the whole world [8].

From 2000s on, morbidity, and mortality related to drug use has become the most important health problem in the whole world, and in some developed countries. Besides in some developed countries mortality rates due to unwanted drug reactions have taken the $4^{\text {th }}$, and $6^{\text {th }}$ place among allcause deaths which constituted $15-20 \%$ of health care expenditures and necessitated establishment of pharmacovigilance systems [4, 9]. Every year nearly ten thousand people lost their lives because of adverse effects of the drugs, and even with the use of registered drugs unwanted, and unexpected adverse effects can be seen [4].

World Health Organization has pointed out to the differences in diseases seen, and prescription routines among countries. These differences involve a wide spectrum of genetic, dietary, and sociocultural variations. Because of differences in the production, dispension, and use of drugs, and also herbal medicinal products which can lead to various toxicological problems among countries, each country should establish its unique national pharmacovigilance system [9]. In Turkey, Turkish Drug, and Medical Device Institution of Turkish Republic (TITCK), Ministry of Health, and Social Welfare, and Turkish Pharmacovigilance Center (TÜFAM) enacted a Regulation Regarding the Monitoring and Assessment of Medicinal Products for Human Use. Our national pharmacovigilance system gained a corporate identity [9]. For effective realization of activities of national pharmacovigilance system, as one of the most important point, all health care professionals should be conscious about the fact that pharmacovigilance is a responsibility which should be shared by all health care professionals $[4,5]$.

Before marketing a drug for the first time, pharmacological properties, and efficacy of the drug are analyzed, and the drug passes through comprehensive, and detailed toksicological, and safety tests. However information about adverse drug reactions can be acquired after postmarketing experience, sophisticated clinical experiments, meta-analyses, and reports of health care professionals about adverse reactions are entered into national, and international databases [9]. As reported in the literature, health care professionals encounter adverse drug reactions at an incidence rate of $1.6-41.4 \%$, and in developed countries, nurses have been playing effective roles in reporting adverse events [10]. Since nurses are the main appliers of human medicinal products in clinics, they are in a position to detect unwanted effects which might develop during the treatment process.

Drug safety are among the priority issues in medicine [11-16]. In developed countries, pharma- 
covigilance studies have gained momentum, however in our country only a few studies have pointed out to deficiencies on this issue [17-20]. Ours is a pilot study which was planned with the aim to imvestigate knowledge, attitude and behaviour of the nurses working in a state hospital about pharmacovigilance, adverse drug reaction and event reporting

\section{MATERIALS AND METHODS}

This descriptive, and cross sectional study was performed with nurses working in Kocaeli Gölcük Necati Çelik State Hospital between January, and March 2013. Approval for the study was obtained from the Ethics Committee of Kocaeli University. The objective of the study was explained to 160 nurses, and among them 112 nurses who gave their consent for participation were included in the study. The questions in the survey were prepared based on "Rational Drug Use Questionnaire -2012" forms issued by Ministry of Health, and Wellfare.

The following items were investigated in the questionnaire:

1. Personal, and professional characteristics (age, professional seniority, the unit she/he is working)

2. What is his/her definition of an adverse effect? a) life-threatening effect b) fatal side-effect c) any side effect of the drug which prolongs hospital stay or necessitates in-hospital treatment d) any side effect which induces congenital anomalies e) all of them

3. How do you react when you encounter an adverse effect? a) I inform the physician or b) the charge nurse c) I fill up safety assessment or d) adverse effect reporting forms.

4. To what authority do you communicate the adverse effects? a) Chief Physician b) The Directorate of the Hospital c) Quality Management Unit d) Authority in Charge of the Pharmacovigilance.

5. To what official organ is notified about your adverse effect report? a) Provincial Directorate of Health b) Ministry of Health c) TÜFAM.

6. What are the minimal adverse effect reporting criteria? a) Name of the person who reported
TABLE1. Personal, and professional characteristics of the nurses who participated in the study

n $\%$

Age groups

18-25

26-35

6

55

5.3

36-50

48

49.1

51-64

3

42.8

Gender

Female

105

7

93.7

Male

6.3

Educational levels

Lycée

15

13.4

High school

50.9

Faculty

57

33.9

Doctorate/post-graduate

Professional life span

$1-3$ years
$4-10$ years
$11-15$ years
$16-19$ years
$\geq 20$ years

adverse effect $b$ ) The name of the patient who used the drug c) The human medicinal product applied d) Name of at least one adverse effect e) The name of the prescribing physician f) The drugs used by the patient g)All of them

\section{Have you ever reported any adverse effect?}

For the statistical analysis SPSS 14.0 (Statistical Package for Social Sciences) for Windows 97 program was used. Evaluation of data was performed using descriptive statistical methods. All analyses were evaluated within $95 \%$ confidence interval, and using two-way ANOVA test.

\section{RESULTS}

Nearly $91.9 \%$ of the study participant nurses were in the 26-50 age group. The study population consisted of $93.7 \%$ female participants, and $98.2 \%$ of them were high school or university graduates. Nearly $75.9 \%$ of the survey participants had 10 


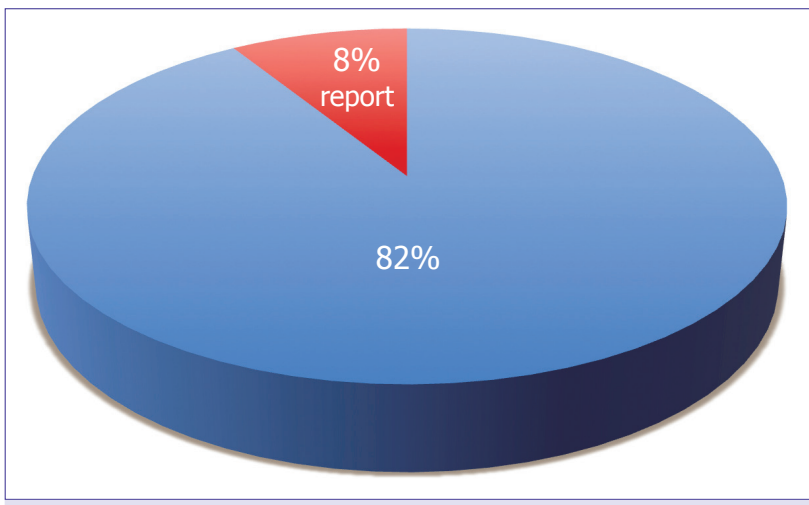

FIGURE 1. ADR reporting rates of the nurses during their professional lives.

or more than 10 years of professional experience. Study participants were outpatient clinic $(n=40$; $35.7 \%$ ), service (internal medicine, $\mathrm{n}=35$; surgical clinics, $n=25)$, or charge nurses $(n=12 ; 10.7 \%)$. Sociodemographic characteristics of the study participants are given in Table 1.

Eighty-three $(74.1 \%)$ nurses who participated in the survey study accurately defined serious side effect. Most of the $(70.5 \%)$ participants knew that they should report any unwanted drug effects they observed during their practice. Thirty percent of the participants indicated that they should inform the prescribing physician about the adverse effect, and $39.2 \%$ of them knew that they should complete the side effect report form. Half of the participants were knowledgeable about minimum reporting criteria. Although $70.5 \%$ of the nurses acknowledged the necessity of reporting drug adverse effects, only $8 \%$ of these nurses reported drug adverse effects during their professional life (Figure 1). The knowledge levels of the participants about pharmacovigilance are given in Table 2 .

Thirty-nine (34.9\%) participants knew that adverse effect reporting should be addressed to the responsible pharmacovigilance authorities, while $25 \%$ of the nurses thought that adverse effects had been communicated to the quality management units. When the knowledge level of the participants about the authorities whom they communicate adverse event reports was inquired, they named City Health Administratives $(n=56 ; 50 \%)$, Ministry of Health $(\mathrm{n}=6 ; 5.4 \%)$, TÜFAM $(\mathrm{n}=9 ; 8 \%)$, and quality management onit $(n=1 ; 0.9 \%)$. While $40(35.7 \%)$ participants indicated that they had not known where to address their adverse event reports.

\section{DISCUSSION}

Since drug-related mortality rates are quiet high worldwide, drug safety is among priorities in medicine [11-16]. Raising awareness about pharmacovigilance, and generalizing adverse effect reporting will not only ensure safe drug use, but also assure determination of specific adverse effects with resultant development of effective treatment modalities [5].

This is a descriptive study investigating awareness, and attitudes of nurses working in the clinics of a state hospital about necessity of ADR reporting. The outcomes of this study have demonstrated that

TABLE2. The knowledge levels of the participants about pharmacovigilance

n

Number (\%) of participants who knew

The defnition of ADR

Necessity of ADR reporting

Necessity for completing ADR report forms

Knowledge level of minimum criteria of reporting

Number of participants who knew that ADR reports should be communicated

to the pharmacovigilance regulatory authorities

Number of participant who knew TÜFAM 
despite awareness of ADR reporting was acknowledged, event reporting rates were still relatively low, and authorities to be addressed were not known.

Many investigations have been performed worldwide on the issue of pharmacovigilance, however nowadays the state of pharmacovigilance in our country has been revealed in only limited number of studies [17-20]. As reported in the literature, health professionals encounter adverse drug reactions at incidence rates varying between 1.6 , and 41.4 percent [10]. Outcomes of the studies realized on the awareness for pharmacovigilance demonstrate variations among countries [21-24] The necessity of ADR reporting was recognized by different percentages of nurses participating in studies performed in China (1.6\%) [22], Nigeria (35\%) [23], and India (75\%).

Although awareness of pharmacovigilance is improved in developed countries, still importance of educational activities has been emphasized in order to increase event reporting rates [10]. Ekman et al. performed a survey study with nurses in Switzerland, and reported event reporting rate as $14 \%$, while this rate climbed to $30 \%$ among those receiving training on pharmacovigilance [21]. In this study, $74.1 \%$ of the nurses knew the unfavourable drug reactions, and $70 \%$ of them were cognizant that they should report adverse effects. However in their professional past, event reporting rates were found to be relatively lower. In three different studies in our country apart from ours, similar, and lower event reporting rates were indicated [18-20]. Sencan et al. realized a educational, and questionnaire survey study in a private hospital with 15 participants, and found that only $60 \%$ of the participant had defined adverse drug reactions correctly [19]. In the study performed by Sencan et al., $60 \%$ of the study participants encountered adverse drug reactions in their professional lives, but their event reportng rates were relatively lower [19]. Majority of our study population were of female gender in the 26-50 age group with an educational level of high school, and higher. Besides they had a professional life of at least 10 years, and they were working in services.

In this investigation, though necessity for reporting adverse drug reactions was already acknowledged in $70.1 \%$ of the study participants, only $9 \%$ of them reported adverse events. Sencan et al. [19], and Alan et al. [20] indicated incidence of event reporting as, 60 , and $65 \%$, respectively. Besides, in our study only $8 \%$ of the study participants were aware of the presence of TÜFAM which achieved a corporate identity. Besides only $8 \%$ of our study participants were aware of the the presence of TÜFAM which gained its corporate identity in 2005. In a survey study of Alan et al. in Adana region only 1.2\% of the participants heard the name of TÜFAM [20]. In another study performed among pharmacists in Istanbul, even though 89 of the pharmacists believed the importance of reporting adverse drug effects, only $7 \%$ of them reported adverse effects to TÜFAM [18].

This is a pilot study conducted with the intention to determine awareness of the nurses working in a state hospital about pharmacovigilance so as to shed light on future studies to be performed. Single-centered design of the study precludes making generalizations. According to the results of this investigation, deficiencies in adverse effect reporting, and lack of knowledge about authorities to be addressed implicate that we are still at the bottom of the ladder.

For the establishment of a national pharmacovigilance system, first of all, awareness should be raised among health care professionals about this issue. In our country, drug side effects are not recorded attentively. However, studies on this issue appear to be promising for the future. Further investigations on pharmacovigilance and especially those concerning causes of deficiencies in adverse event reporting should be performed.

Conflict of Interest: No conflict of interest was declared by the authors.

Financial Disclosure: The authors declared that this study has received no financial support.

\section{REFERENCES}

1. Turan N. İlaca bağlı advers etki takibi ve Türkiyéde antibiyotiklerin kayıtlı advers etkileri. Ankem Derg 2003;17:326-8.

2. Lindquist M, Edwards IR. The WHO Programme for International Drug Monitoring, its database, and the technical support of the Uppsala Monitoring Center. J Rheumatol 2001;28:1180-7.

3. Edwards IR. The WHO World Alliance for Patient Safety: a new 
challenge or an old one neglected? Drug Saf 2005;28:379-86.

4. Çakır N. Deney Tüpünden Eczane Rafina: Bir Antimikrobiyal Nasıl Geliştirilir? ANKEM Derg 2010;24:174-81.

5. Routledge P. 150 years of pharmacovigilance. Lancet 1998;18:1200-1. CrossRef

6. Botting J. The History of Thalidomide. Drug News Perspect 2002;15:604-611. CrossRef

7. Waller P. An introduction to pharmacovigilance. In:What is Pharmacovigilance and How has it Developed? Wiley online publication. 2009;1-10. DOI: 0.1002/9781444316766.ch1

8. Edwards R. Advers Drug Reactions. In: Drug Benefits and Risks: International Textbook of Clinical Pharmacology. Boxtel CH, Santoso B, Edwars R. Eds, London, John Wiley \&Sons ltd 2007:195-211.

9. Akılcı A, Dağıstanlı S, Aydınkarahaliloğlu D, Şardaş S. Ulusal Farmakovijilans Sistemi. Türk Farmakoloji Derneği Klinik Farmakoloji Çalışma Grubu Elektronik Bülteni 2005;3:19-22. www.tdf.org.tr

10. Shepherd M. Adverse reactions: know the risks. Nurs Times 2011;107:20.

11. Lesar T, Mattis A, Anderson E, Avery J, Fields J, Gregoire J, et al. Using the ISMP Medication Safety Self-Assessment to improve medication use processes. Jt Comm J Qual Saf 2003;29:211-26.

12. Leape LL, Bates DW, Cullen DJ, Cooper J, Demonaco HJ, Gallivan T, et al. Systems analysis of adverse drug events. ADE Prevention Study Group. JAMA 1995;274:35-43. CrossRef

13. Barker KN, Flynn EA, Pepper GA, Bates DW, Mikeal RL. Medication errors observed in 36 health care facilities. Arch Intern Med 2002;162:1897-903. CrossRef

14. Kayaalp S. Rasyonel Tedavi Yönünden Tibbi Farmakoloji. 12. Bask1, Ankara, 2009.

15. Akici A, Oktay S. Rational pharmacotherapy and pharmacovigilance. Curr Drug Saf 2007;2:65-9. CrossRef
16. Sodha M, McLaughlin M, Williams G, Dhillon S. Nurses' confidence and pharmacological knowledge: a study. Br J Community Nurs 2002;7:309-15. CrossRef

17. Soyalan M, Demirdamar R, Toklu HZ, Gümüșel B. Kuzey Kibris Türk Cumhuriyeti'nde ulusal farmakovijilans sistemi ve mevcut uygulamalar. Marmara Pharmaceutical Journal 2012;16:159-63. CrossRef

18. Toklu HZ, Uysal MK. The knowledge and attitude of the Turkish community pharmacists toward pharmacovigilance in the Kadikoy district of Istanbul. Pharm World Sci 2008;30:556-62.

19. Şencan N, Altınkaynak M, Ferah I, Özyıldırım A, Ceylan E, Clark P. The Knowledge and Attitudes of Physicians and Nurses Towards Advers Event Reporting and the Effect of Pharmacovigilance Training: A Hospital Experience. Hacettepe University Journal of the Faculty of Pharmacy 2010;30:24-40.

20. Alan S, Ozturk M, Gokyildiz S, Avcibay B, Karataş Y. An evaluation of knowledge of pharmacovigilance among nurses and midwives in Turkey. Indian J Pharmacol 2013;45:616-8. CrossRef

21. Ekman E, Petersson G, Tågerud S, Bäckström M. Awareness among nurses about reporting of adverse drug reactions in Sweden. Drug Healthc Patient Saf 2012;4:61-6. CrossRef

22. Li Q, Zhang SM, Chen HT, Fang SP, Yu X, Liu D, et al. Awareness and attitudes of healthcare professionals in Wuhan, China to the reporting of adverse drug reactions. Chin Med J (Engl) 2004;117:856-61.

23. Fadare JO, Enwere OO, Afolabi AO, Chedi BA, Musa A. Knowledge, attitude and practice of adverse drug reaction reporting among healthcare workers in a tertiary centre in Northern Nigeria. Trop J Pharm Res 2011;10:235-42. CrossRef

24. Rehan HS, Sah RK, Chopra D. Comparison of knowledge, attitude and practices of resident doctors and nurses on adverse drug reaction monitoring and reporting in a tertiary care hospital. Indian J Pharmacol 2012;44:699-703. CrossRef 